\title{
Lateral
}

Journal of the Cultural Studies Association

\section{Review of Media Hoaxing: The Yes Men and Utopian Politics by lan Reilly (Lexington Books)}

by Natalia Kovalyova | Book Reviews, Issue 9.2 (Fall 2020)

ABSTRACT The review evaluates lan Reilly's analysis of Yes Men hoaxes as a means of calling attention to corporate greed and abuses of power as well as a new mode of political engagement that entails from utopian dispositions the reformist aspirations to nudge society towards a better version of itself. It emphasizes the innovative approach for of The Yes Men to "sharpening a political critique" and coupling it with doing politics differently. It highlights Reilly's findings of the dependency of hoaxes' success on contextual factors and encourages future studies to capitalize on Reilly's work to develop an account of the "ecosystem" in which media hoaxes circulate.

KEYWORDS $\underline{\text { media, }} \underline{\text { politics, }} \underline{\text { utopia }}$

Media Hoaxing: The Yes Men and Utopian Politics. By lan Reilly. New York, NY:

Lexington Books, 2018, 192 pp. (hardback) ISBN: 9781498527354 . US List: $\$ 90$.

Humor and practical jokes that demand social change span centuries and genres as different as Jonathan Swift's "A Modest Proposal" published in 1729 and The Daily Show with Jon Stewart, which aired between 1999 and 2015. In his book, Media Hoaxing: The Yes Men and Utopian Politics, lan Reilly focuses on the work of The Yes Men-a creative duo whose performances blend style, politics, and tactics aiming to sharpen the political critique and shape public opinion on important social issues. Having examined The Yes Men's work from 1996 onward in order to understand the cultural form and practice of contemporary media hoaxing, Reilly argues that their hoaxes are effective not only in calling attention to corporate greed and abuses of power but also as a new mode of political engagement for advancing a common good. In their work, the two artists-turnedactivists capitalize on the traditional media's competitive rush to be "first to publish" and on their propensity for the sensational in order to disseminate their message and reach audiences covered by print and television. Using these strategically staged performances designed with media coverage in mind, The Yes Men operate at once "outside and within the established discourses of traditional news media" (3) and stand out for their emphasis on audience engagement and on cultivation of utopian ethos (8). Although Reilly does not expand on the "utopian" element here, it merits to spell out how a utopian outlook contributes to the institutional critique that The Yes Men's pranks deliver. Specifically, contrary to a common view of utopia as unrealistically perfect arrangement for society, utopian dispositions align well with the reformist aspirations of those who strive to nudge society towards a better version of itself; hence Reilly's reading of The Yes Men performances as a genuine political intervention. 
From a brief survey of hoaxing as a communicative form with a long history that is laid out in Chapter 1, Reilly assembles a list of outcomes by which to measure its successes and failures, including such factors as the level of attention, publicity and notoriety, a degree of believability, a degree of indemnification of the target, blending of entertainment and instruction, and several others. In Chapter 2, he focuses attention on journalism as a practice that responds to critical situations, and that is compatible with hoaxing as one of its tools. Reilly then applies his analytical framework of sorting into successes and failures across twenty years of The Yes Men activities. Chapter 3 takes up unsuccessful hoaxes first and shows that notoriety neither equates with nor translates into a politically influential force on public terrain. In fact, Reilly shows, The Yes Men hoaxes have made poor entries into public discussions of social injustices and inequalities inflicted by corporate greed and outright lies. They did not become levers for changing the direction of those discussions but rather served as a definitive pivot in a later turn of The Yes Men to educational projects.

Chapter 4 looks into successful hoaxes and finds them contextually dependent on multiple factors (85-86). To put it in other words, The Yes Men's "official" disbanding of the WTO, their public "acceptance of full responsibility" for the Bhopal accident on behalf of the Dow Chemical, and the GWBush.com hoax that prompted the then candidate George W. Bush to infamously suggest that "there ought to be limits on freedom of speech" (88)—all succeeded because of a unique match of communicative strategies to specific configurations of context and key players within it. This finding places media activism squarely into the realm of rhetorical arts and highlights the importance of the fine-tuning of available means of persuasion to multiple audiences. Unfortunately, Reilly's focus on shaming corporations costs him a nuanced analysis of this complexity and the divergent effects it generates. For instance, while in the Dow Chemical hoax The Yes Men may not have imagined the victims of corporate irresponsibility as their primary audience, those people were directly involved in-and affected by-the Dow actions. Therefore, their reactions to a hoax should have been considered (and anticipated) more carefully, as the aftermath of the hoax strongly suggested.

The final chapter of the book is devoted to the Yes Lab and the initiative "to train, mentor, and guide future changemakers" (113), to facilitate grassroots movements, and to increase public involvement. While the evolution of the duo from pranks to training programs seems an obvious trajectory, its crowning effect may very well be a function of a narrative order of Reilly's presentation that starts from failures and moves to successes. Moreover, placing the hoaxes mentioned in the book on a timeline, one cannot help but notice that there is no early, marred-by-failures stage in the Yes Men career that is later replaced by more successful interventions as they grow into savvier professionals. Instead, a series of their successful hoaxes have been followed by grand failures, calling for a more sophisticated analysis of these types of interventions, rather than sorting them into failures and successes.

One obvious step for future explorations is to engage with criticisms of The Yes Men, both by the traditional media complaining about the undermined credibility and integrity that hoaxing leaves behind as well as by the victims of corporate recklessness upon whom hoaxing inflicts additional suffering when its false promises are revealed as such. Building on Reilly's discovery of a strong contextual dependency of each individual hoax, it will be important to develop an account of the "ecosystem" that hoaxing enters, and to deduce the norms and regulations within it that sink some hoaxes, while allowing others to succeed. Reilly's study will form a solid foundation for such work and for the efforts to 
move beyond reimagining of the world, and towards theorizing a path for the utopian ethos of concrete decisions and transformative actions. Such advances would assist media activists in a very practical manner as they select forms and formats for maximum effect.

One point of caution, however, applies to deploying Reilly's descriptions of measures of success. Somewhat critical of clickbait and lapses of accuracy in the traditional media organizations, Reilly exhibits unwavering enthusiasm for media activism of the Yes Men brand. Moreover, he is undisturbed neither by the language of efficiency and measurable outcomes, nor by the neoliberal logic invited by such terminology into creative work that attempts to disrupt our buy-in into the notion of corporate social responsibility. As the book's narrative bends towards The Yes Men's successes, one wonders whether the narrative couched in terms of "outcomes," "metrics," and "impact" unwittingly normalizes media activism and makes it a part of the neoliberal media ecology, thus running against the group's more radical aspirations.

These clearly entailed next steps speak to the strengths of the book, whose lucid presentation makes it accessible to the general public, to media activists who look for tips on their projects in the historical precedents detailed in the book, and to students who make their entry into the world of academic scholarship and crave a more direct and immediate connection between research and the burning issues of the day. The Yes Men's experiences as described in this book sets up a solid launching pad from which to theorize, to experiment with, and to advocate for a new relationship between media genres and practices, creative activism, and social change.

\section{Author Information}

\section{Natalia Kovalyova}

Natalia Kovalyova is master's student at the iSchool at UT Austin studying the relationships between discourse and power in a variety of contexts. Her most recent research focuses on the enduring patterns of control over public memory, group identities, and knowledge making in cultural heritage institutions. She is a member of the National Communication Association, Rhetoric Society of America, and the Society of American Archivists.

View all of Natalia Kovalyova's articles.

\section{Article details}

Natalia Kovalyova, "Review of 'Media Hoaxing: The Yes Men and Utopian Politics' by lan Reilly (Lexington Books)," Lateral 9.2 (2020).

https://doi.org/10.25158/L9.2.17

This content is licensed under a Creative Commons Attribution-NonCommercial 4.0 International 
License. Copyright is retained by authors.

Lateral is the peer-reviewed, open access journal of the Cultural Studies Association.

ISSN 2469-4053 